\title{
Work stress and job satisfaction of community health nurses in Southwest China.
}

\author{
Lin Tao", Hongxia Guo", Suzhen Liu*, Jiping Li \\ West China Hospital/West China School of Nursing, Sichuan University, Sichuan, PR China \\ \#These authors contributed equally to this work
}

\begin{abstract}
Purpose: To explore the correlation between work stress and job satisfaction in Community Health Nurses (CHNs) in Southwest of China.

Backgrounds: Work stress and job satisfaction are interacting factors and together with demographic characteristics, contribute to working motivation in nurses. Little is known about status of those factors in Southwest of China where CHNs are detrimentally important for meeting the explosively increasing demands of citizens to community health services.

Methods: This was across-sectional survey and analysis based on questionnaires related to demographic status, work stress and job satisfaction of 969 nurses from 56 CHS centers in 12 prefectural-level cities of Sichuan Province located in Southwest China.

Results: Work stress and job satisfaction of CHNs in Sichuan Province were moderate and negatively correlated $(p<0.001)$. Among demographic profiles, age, educational, job training on community nursing were significant contributors for job satisfaction $(\mathbf{p}<\mathbf{0 . 0 5})$. Among work stresses, professional and career advancement, work environment and resources, management and interpersonal relationships, and workload and work duration were significant contributors for job satisfaction $(\mathbf{p}<\mathbf{0 . 0 5})$.

Conclusions: This study indicated possible significantly negative effects of work stress on job satisfaction of CHNs in Southwest China, approaches to releasing work stress, increasing opportunities for job training and continuing education, raising salary and improving promotion system are therefore highly recommended.
\end{abstract}

Keywords: Community health nurses, Work stress, Job satisfaction.

\section{Introduction}

Until now, work stress and job satisfaction among nurses have been of great concern for researchers worldwide because of the ongoing nurse shortage and high turnover. As front-line healthcare providers, nurses are always overloaded with work, which threatens their physical and mental health [1,2]. Special working environments and work content contribute to the high rate of work stress that nurse's experience compared to other industries, and 9.20-68.0\% of nurses suffer from work stress globally [3]. In the United States, more than $60 \%$ of nurses perceived moderate or even high levels of work stress [4]. A Brazilian survey found $15.2 \%$ of nurses presented with severe work stress [5]. Work stress is thought to be a major contributor to burnout and positively correlated with resignation intention [6]. A recently published survey reveals that a high turnover rate of nurse indirectly increases work stress in staff who remain [7]. Thus, this topic has attracted widespread concern about how to keep nurse teams stable by managing work stress effectively.
However, job satisfaction has been viewed as the strongest predictor of nurses' retention and the loss of nurses could be decreased through strengthening the management of their job satisfaction $[8,9]$. In recent years, approximately $40 \%$ of nurses in Hong Kong [10] and 56\% in mainland China [11] have experienced job dissatisfaction, warning that nursing managers and policy makers should address the concerns of job satisfaction especially when there is increasingly shortage of nurses currently.

There is no doubt that we must consider work stress and job satisfaction as a long-term issue. Previous studies [12,13] have largely concentrated on the status of hospital nurses' work stress or job satisfaction as well. Like nurses working in hospitals, Community Health Nurses (CHNs) are also one of the most important parts of the healthcare workforce. However, their care modes are different from hospital nurses, involving health promotion, health protection, disease prevention, treatment, rehabilitation, and family planning, which provide not only for individuals including patients, but give more consideration to families, aggregates, or the whole community. 
CHNs usually work outside of the hospital as a modern health gatekeeper, which can be described as caregiver, organizer and manager, quality controller, health educator, coordinator and collaborator, agent of connectivity, advocate, researcher, and so on $[14,15]$. In most countries, these roles are usually played by different types of CHNs [16-18], who have their own specialties such as public health nursing, faith community nursing, home health nursing, health visiting nursing, school nursing, occupational health nursing, and specialties practicing both in the community and hospitals, such as psychiatric nursing, nurse midwifery, geriatric nursing, palliative care nursing, rehabilitation nursing, disease control nursing, etc. $[19,20]$.

However, there is limited evidence regarding work stress and job satisfaction of CHNs. Studies in London and Hong Kong showed that community psychiatric nurses were generally more stressed than their hospital counterparts [21,22]. The results mainly focused on community psychiatric nurses, which are one of the various types of CHNs, but several studies have also revealed that $\mathrm{CHNs}$ felt high levels of frustration, so that $40 \%$ of them were prone to leave their work in the UK [23] and approximately $50 \%$ of primary health care nurses experienced work stress in Saudi Arabia [24]. Evidently, this indicates that work stress among $\mathrm{CHNs}$ is high enough in general. However, levels of CHNs' job satisfaction differ across various regions. For instance, $56 \%$ of $\mathrm{CHNs}$ were satisfied or very satisfied with their present job in Ghana [25]; $57 \%$ of CHNs including district nurses, community nurses, community matrons, case managers, nurse specialists, or others reported that they were satisfied in the UK [23]; however, in Australia, the level of primary health care nurses' job satisfaction reached to/by $80 \%$ [26]. In this context, research directly exploring the relationships between work stress and job satisfaction among $\mathrm{CHNs}$ remains scant [27,28]. Thus, there is a need to directly explore work stress and job satisfaction in greater depth from the CHNs' perspective.

What is the situation in China? To achieve the goal of "Health for All," from 1997, the Chinese government started to positively develop Community Health Services (CHS) as part of health care system reform in China, and has been taking a series of measures to encourage nurses to work in the community. By the end of 2015, there were 1.54 million Chinese registered nurses working in CHS centers as CHNs, accounting for $30 \%$ of all community medics, and the doctornurse ratio reached 1:1.05 which basically meet the national requirement [29]. However, the figure still represents a serious shortage of CHNs in China. Yet, more than this, despite the gradually increase in quantity, the quality of the community nursing workforce in China is lower compared with other countries. Nearly $88.0 \%$ of Chinese CHNs did not receive undergraduate education and some of them had never received job training in community nursing [29]. In the meanwhile, more than two-third of CHNs only held a primary professional title [29]. This indicates that their professional level was low. Under the circumstances, Chinese $\mathrm{CHNs}$ are burdened with public health service and basic medical services concurrently. For instance, they not only provide residents with a free package of 46 public health services in thirteen categories including health records, health education, preventive inoculation, healthcare for children under six, healthcare for pregnant and lying-in women, healthcare for elderly people, treatment for hypertension and type II diabetes patients, treatment for tuberculosis, healthcare for severe psychosis patients, reporting and handling of infectious diseases and public health emergencies, healthcare supervision and coordination, and traditional Chinese medicine health services, but also provide basic medical nursing such as caring for patients directly, community-based ward nursing, out-patient care, and so on. The insufficient quantity and lower quality creates difficulties for $\mathrm{CHNs}$ in undertaking a variety of roles simultaneously.

Furthermore, Chinese CHNs usually undertake non-nursing jobs such as logistics service, medical insurance reimbursement, and out-patient registration because of insufficient staffing. This burdens $\mathrm{CHNs}$ with work pressure and may influence their job satisfaction. However, few studies have focused on exploring the status of work stress and job satisfaction among CHNs. Furthermore, their conclusions remain inconsistent: they have shown different levels of work stress or job satisfaction for Chinese CHNs [30-32]. In addition, most surveys have mainly been conducted in economically developed regions, while few have been conducted in underdeveloped areas, especially in Southwest China. Moreover, large-scale and multicenter research into work stress and job satisfaction regarding CHNs' situation remains lacking. Hence, it is necessary to pay more attention to work stress and job satisfaction of CHNs.

In the present study, we studied the situation of CHNs in Southwest China, investigated factors involved in work stress and the demographic characteristics of CHNs, and quantified their job satisfaction, thus documenting basic perspectives of work stress and motivation in CHNs. Furthermore, we analysed the contributors of job satisfaction via a crosssectional survey that examined demographic characteristics, work stress, and job satisfaction. Our study will be informative for policy makers to improve the situation of $\mathrm{CHNs}$ through better management.

\section{Methods}

\section{Sample}

A descriptive cross-sectional design was conducted. Fifty-six CHS centers were conveniently sampled in the provincial capital city (Chengdu) as well as 11 from 18 prefectural-level cities that were classified into 4 economic areas (including provincial capital city, Chengdu and Panxi area, South and North-East economic areas) in the Sichuan province, China. All data collection procedures were approved by these CHS centers where all nurses were invited. The inclusion criteria were as follows: (a) being a registered nurse, (b) practicing for more than 6 months in the CHS center, and (c) consenting to participate in this study voluntarily. The exclusion criteria were as follows: (a) student nurses, (b) nurses in vacation during the 
investigation of the CHS centers, (c) nurses in their probationary period, and (d) those who failed to complete the questionnaires.

\section{Assessments and questionnaires}

A questionnaire consisting of three parts was used in this survey. The first part of the survey questionnaire was demographic profile including economic area of practice, gender, age, education in nursing, mate, professional title, nursing experience before being $\mathrm{CHN}$, years of experience as a nurse, years of experience as a $\mathrm{CHN}$, job training on community nursing. The second was Work Stress Scale of Chinese Community-Health Nurses (referred as Work Stress Scale hereafter) modified from Occupational Stressor Scale [33]. It consisted of 40 items classified into 5 domains: (a) professional and career advancement, (b) working environment and resources, (c) workload and time, (d) patient care, and (e) management and interpersonal relationship. A 4-point scale could be scored where 1 represented "strongly disagree" and 4 represents "strongly agree". The mean score of the total scale and each domain which were average scores of their items were calculated with higher scores indicating higher stress. The scores were transformed to percent equivalents of raw score according to the classification standards established by Ayamolowo et al. [34]. CHNs that scored $\geq 70 \%$ were grouped as having high work stress, 40-69\%, average work stress, and $<40 \%$, low work stress. The scale's internal consistency was 0.98 measured via the Cronbach's alpha. Content of the Work Stress Scale is based on and reviewed by an expert panel including 5 experts and Content Validity Index (CVI) is 0.97 . The validity of questionnaire was determined by means of factor analyses. A exploratory factor analysis of the work stress scale resulted in the values for the cumulative contribution rate of five factors being $68.61 \%$, and the factor loading value of 40 items were more than 0.5 .

The third was the Job Satisfaction Scale of Chinese Community-Health Nurses (referred to as the Job Satisfaction Scale hereafter) developed based on the Nurse Job Satisfaction Assessment Scale [35] and Home Healthcare Nurses' Job Satisfaction Scale [36]. The questionnaire consisted of 35 items classified into 8 domains including: (a) salary and benefits, (b) work itself, (c) workload, (d) management, (e) professional development, (f) balance of family and work, (g) recognition, and $(\mathrm{h})$ coworker relationships. A 5-point scale could be scored where 1 represented "strongly disagree" and 5 represented "strongly agree." Negatively worded items were reverse scored. The scoring of the total scale and domain was the same as the work stress scale: the mean score of the total scale and each domain were average scores of their items. Thus, higher scores indicated greater job satisfaction. Level of CHNs' job satisfaction was grouped into three categories of high degree of job satisfaction ( $\geq 70 \%$ ), average degree of job satisfaction (40-69\%), low degree of job satisfaction $(<40 \%)$ [34]. Its Cronbach's alpha was 0.86 and content validity ratio was 0.98 . The validity of questionnaire was also determined by means of factor analyses. A exploratory factor analysis of the Job satisfaction Scale resulted in the values for the cumulative contribution rate of eight factors was $60.43 \%$ and its factor loading value of 35 items was more than 0.5 .

\section{Data collection procedure}

Questionnaires and corresponding guidance documents were sent to the manager of each CNS center and were also well explained online. The managers distributed the questionnaires to the nurses according to the inclusion and exclusion criteria. All procedures including the purpose, methods, procedures, significance, and right to refuse were well explained to the individual nurses in a face-to-face manner. Questionnaires were completed anonymously and individually and returned to the managers within one week. In total, 1,015 questionnaires were distributed and returned; 969 (95.5\%) were completed in a valid manner.

\section{Data analysis}

Epidata 3.1 was adopted for database development and SPSS 19.0 software was used for statistical analyses in which descriptive statistics for the demographic data, Pearson's correlations, and stepwise multiple regression analysis was applied. All analyses were repeated at least three times by different people. Significance was accepted as $p<0.05$.

\section{Results}

\section{Demographic information of the CHNs}

Of the 969 valid respondents, 37\% came from the provincial capital city. Females were $99.1 \%$. More than two-thirds $(68.6 \%)$ were under 35 years old. Most of the sample $(67.9 \%)$ was married. Respondents that held an associate degree in nursing were $57.3 \%$ and $79.6 \%$ of the respondents had a primary professional title as a junior or senior nurse. Only $6.5 \%$ had worked as CHNs for more than 10 years and $40.8 \%$ of the nurses had worked in a hospital for more than 10 years (Table 1).

\section{Work stress and job satisfaction}

The overall mean score of the Work Stress Scale was $2.17 \pm$ 0.53. Among the work stress domains, working environment and resources, and management and interpersonal relationships had the highest $(2.49 \pm 0.74)$ and lowest $(1.78 \pm 0.59)$ mean scores, respectively. The overall mean score on the job satisfaction scale was $3.39 \pm 0.41$. Its domain of coworker relationships obtained the highest score $(4.03 \pm 0.63)$ and salary and benefits was given the lowest score $(2.32 \pm 0.81)$ (Table 2). A majority (73.5\%) of CHNs had average degree of work stress and more than half $(58.2 \%)$ of $\mathrm{CHNs}$ were in moderate level of job satisfaction (Figure 1).

\section{Correlation between work stress and job satisfaction}

A negative correlation between work stress and job satisfaction was revealed with the Pearson's correlation $(\mathrm{r}=-0.58)$; such correlations were also significant for work stress related factors 
(Table 3), suggesting that higher work stress leads to lower job satisfaction.

\section{Contribution of work stress and demographics in job satisfaction}

Stepwise multiple regression analyses indicated that age, education, job training on community nursing, professional and career advancement, work environment and resources, management and interpersonal relationships, and workload and time, cumulatively contributed to job satisfaction significantly and explained $37.5 \%$ of the variance of job satisfaction (Table 4).

Table 1. Descriptive statistics for CHNs overall work stress and job satisfactions core.

\begin{tabular}{|c|c|c|c|c|c|c|c|}
\hline \multirow[t]{2}{*}{ Variables (\%) } & \multirow[t]{2}{*}{ Frequency $(\%)$} & \multicolumn{3}{|c|}{ Work stress } & \multicolumn{3}{|c|}{ Job Satisfaction } \\
\hline & & Mean SD & F-value & $\mathbf{p}$ & Mean SD & F-value & $\mathbf{p}$ \\
\hline \multicolumn{2}{|l|}{ Economic area of practice } & & 20.969 & $0.000^{* *}$ & & 8.814 & $0.000^{* *}$ \\
\hline Provincial capital city ${ }^{a}$ & $359(37.0)$ & 2.02 & 0.48 & & 3.48 & 0.35 & \\
\hline Chengdu and Panxi area ${ }^{b}$ & $111(11.5)$ & 2.29 & 0.52 & & 3.36 & 0.48 & \\
\hline South area & $283(29.2)$ & 2.33 & 0.57 & & 3.33 & 0.42 & \\
\hline North-east area & $216(22.3)$ & 2.16 & 0.49 & & 3.36 & 0.42 & \\
\hline \multicolumn{2}{|l|}{ Gender } & & 0.015 & 0.904 & & 0.305 & 0.581 \\
\hline Males & $9(0.9)$ & 2.19 & 0.59 & & 3.47 & 0.42 & \\
\hline Females & $960(99.1)$ & 2.17 & 0.53 & & 3.39 & 0.41 & \\
\hline \multicolumn{2}{|l|}{ Age range $(y)$} & & 10.467 & $0.000^{* *}$ & & 6.384 & $0.000^{* *}$ \\
\hline$\leq 24$ & $244(25.1)$ & 2.04 & 0.52 & & 3.48 & 0.43 & \\
\hline $25-34$ & $421(43.5)$ & 2.17 & 0.52 & & 3.38 & 0.39 & \\
\hline $35-44$ & $206(21.3)$ & 2.26 & 0.54 & & 3.36 & 0.39 & \\
\hline$\geq 45$ & $98(10.1)$ & 2.34 & 0.51 & & 3.3 & 0.43 & \\
\hline \multicolumn{2}{|l|}{ Education in nursing } & & 0.589 & 0.555 & & 3.261 & $0.039^{*}$ \\
\hline Vocational high school & $261(26.9)$ & 2.17 & 0.55 & & 3.34 & 0.46 & \\
\hline Associate degree & $555(57.3)$ & 2.16 & 0.53 & & 3.41 & 0.39 & \\
\hline Bachelor degree & $153(15.8)$ & 2.22 & 0.49 & & 3.43 & 0.38 & \\
\hline \multicolumn{2}{|l|}{ Mate } & & 23.829 & $0.000^{* *}$ & & 4.113 & $0.043^{*}$ \\
\hline Yes & $658(67.9)$ & 2.23 & 0.54 & & 3.38 & 0.41 & \\
\hline No & $311(32.1)$ & 2.05 & 0.49 & & 3.43 & 0.4 & \\
\hline \multicolumn{2}{|l|}{ Professional title } & & 12.318 & $0.000^{* *}$ & & 5.518 & $0.004^{*}$ \\
\hline Junior nurse & $391(40.4)$ & 2.08 & 0.53 & & 3.44 & 0.42 & \\
\hline Senior nurse & $380(39.2)$ & 2.21 & 0.52 & & 3.34 & 0.41 & \\
\hline Nurse-in-charge and above & $198(20.4)$ & 2.29 & 0.51 & & 3.41 & 0.37 & \\
\hline \multicolumn{2}{|c|}{ Nursing experience before being $\mathrm{CHN}$} & & 2.943 & 0.087 & & 1.257 & 0.263 \\
\hline Yes & $786(81.1)$ & 2.19 & 0.53 & & 3.39 & 0.4 & \\
\hline No & $183(18.9)$ & 2.11 & 0.53 & & 3.43 & 0.44 & \\
\hline \multicolumn{2}{|c|}{ Years of experience as a nurse $(y)$} & & 8.487 & $0.000^{* *}$ & & 3.726 & $0.011^{*}$ \\
\hline$\leq 5$ & $341(35.2)$ & 2.07 & 0.49 & & 3.45 & 0.41 & \\
\hline $6-10$ & $233(24.0)$ & 2.18 & 0.52 & & 3.38 & 0.4 & \\
\hline
\end{tabular}


Work stress and job satisfaction of community health nurses in Southwest China

\begin{tabular}{|c|c|c|c|c|c|c|c|}
\hline $11-15$ & $151(15.6)$ & 2.23 & 0.56 & & 3.35 & 0.39 & \\
\hline$>15$ & $244(25.2)$ & 2.28 & 0.55 & & 3.35 & 0.42 & \\
\hline Years of experience as a $\mathrm{CHN}(\mathrm{y})$ & & & 4.13 & $0.006^{*}$ & & 0.916 & 0.433 \\
\hline$<3$ & $397(41.0)$ & 2.11 & 0.54 & & 3.41 & 0.42 & \\
\hline 3-5 & $274(28.3)$ & 2.21 & 0.49 & & 3.36 & 0.42 & \\
\hline $6-10$ & $235(24.2)$ & 2.25 & 0.56 & & 3.4 & 0.37 & \\
\hline$>10$ & $63(6.5)$ & 2.11 & 0.49 & & 3.42 & 0.4 & \\
\hline Job training on community nursing & & & 0.8 & 0.371 & & 10.367 & $0.000^{* *}$ \\
\hline Yes & 715 (73.8) & 2.16 & 0.53 & & 3.42 & 0.39 & \\
\hline No & $254(26.2)$ & 2.2 & 0.52 & & 3.32 & 0.44 & \\
\hline
\end{tabular}

Note: aprovincial capital city just refers to Chengdu city. because of small number of participants and the same economic status, Chengdu and Panxi area were combined (Chengdu area refers to the Chengdu's neighbouring cities); ${ }^{* *} p<0.001,{ }^{*} p<0.05$.

Table 2. Status of CHNs' work stress and job satisfaction.

\begin{tabular}{lccc}
\hline Parameters & Mean & SD & Range \\
\hline Work stress & 2.17 & 0.53 & $1.00-4.00$ \\
\hline Management and interpersonal relationships & 1.78 & 0.59 & $1.00-4.00$ \\
\hline Patient care & 2.14 & 0.59 & $1.00-4.00$ \\
\hline Workload and time & 2.27 & 0.71 & $1.00-4.00$ \\
\hline Professional and career advancement & 2.44 & 0.61 & $1.00-4.00$ \\
\hline Working environment and resources & 2.49 & 0.74 & $1.00-4.00$ \\
\hline Job satisfaction & 3.39 & 0.41 & $1.83-4.54$ \\
\hline Salary and benefits & 2.32 & 0.81 & $1.00-4.33$ \\
\hline Work itself & 3.03 & 0.53 & $1.00-5.00$ \\
\hline Professional development & 3.05 & 0.68 & $1.00-4.80$ \\
\hline Workload & 3.12 & 0.45 & $1.60-5.00$ \\
\hline Management & 3.66 & 0.76 & $1.00-5.00$ \\
\hline
\end{tabular}

\begin{tabular}{llll}
\hline Balance of family and work & 3.79 & 0.66 & $1.67-5.00$ \\
\hline Recognition & 3.83 & 0.59 & $1.57-5.00$ \\
\hline Coworker relationships & 4.03 & 0.63 & $1.00-5.00$ \\
\hline
\end{tabular}

Table 3. Negative correlation between work stress and job satisfaction.

\begin{tabular}{ll}
\hline Parameters & Job satisfaction \\
\hline Total work stress & $-0.58^{* *}$ \\
\hline Management and interpersonal relationship & $-0.50^{* *}$ \\
\hline Patient care & $-0.46^{* *}$ \\
\hline Workload and time & $-0.47^{* *}$ \\
\hline Professional and career issues & $-0.54^{* *}$ \\
\hline Working environment and resources & $-0.46^{* *}$ \\
\hline Note: ${ }^{* *} p<0.001$ & \\
\hline
\end{tabular}

Table 4. Stepwise multiple linear regression predicting job satisfaction among CHNs.

\begin{tabular}{|c|c|c|c|c|c|c|c|}
\hline \multirow[t]{2}{*}{ Variables } & \multicolumn{2}{|c|}{$\begin{array}{l}\text { Unstandardized } \\
\text { coefficients }\end{array}$} & \multirow[t]{2}{*}{$\begin{array}{l}\text { Standardized } \\
\text { coefficients (Beta) }\end{array}$} & \multirow[t]{2}{*}{$\mathbf{T}$} & \multirow[t]{2}{*}{ p-value } & \multicolumn{2}{|c|}{$95 \%$ confidence interval for $\beta$} \\
\hline & B & Std-error & & & & Lower bound & Upper bound \\
\hline Constant & 4.229 & 0.056 & & 75.023 & $0.000^{* *}$ & 4.272 & 4.514 \\
\hline Age & -0.024 & 0.012 & -0.054 & 75.023 & $0.044^{*}$ & -0.048 & -0.001 \\
\hline Education & 0.057 & 0.016 & 0.091 & 3.523 & $0.000^{* *}$ & 0.025 & 0.09 \\
\hline Job training on community nursing & 0.082 & 0.024 & 0.088 & 3.436 & $0.001^{*}$ & 0.035 & 0.129 \\
\hline Professional and career advancement & -0.194 & 0.025 & -0.289 & -7.801 & $0.000^{* *}$ & -0.243 & -0.145 \\
\hline $\begin{array}{l}\text { Management and Interpersonal } \\
\text { relationship }\end{array}$ & -0.156 & 0.023 & -0.224 & -6.631 & $0.000^{* *}$ & -0.202 & -0.11 \\
\hline Working environment and resources & -0.047 & 0.022 & -0.086 & -2.178 & $0.030^{*}$ & -0.09 & -0.005 \\
\hline
\end{tabular}




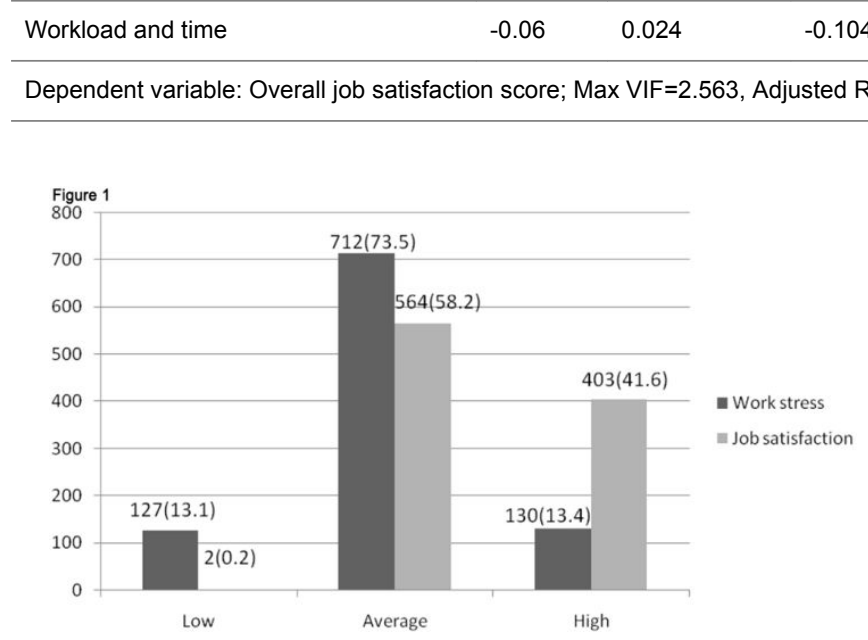

Figure 1. The classification of CHNs' work stress and job satisfaction.

\section{Discussion}

This was a large-scale study investigating the correlation between work stress and job satisfaction in CHNs' in Southwest of China. The majority of CHNs in this study was young women under 35 years old, but had education below university in nursing, and held lower professional title, and had less CHNs experience than 5 years. A total of $18.9 \% \mathrm{CHNs}$ didn't have nursing experience in hospital before being a $\mathrm{CHN}$, and $26.2 \%$ didn't get any job training on CHNs. These may imply professional competence of CHNs in China is insufficient.

Work stress in healthcare industry has been a long-standing concern [37]. This finding revealed that CHNs in Southwestern China experienced moderate stress. The average score was lower than those reported for CHNs in east coastal area of China [30], but higher than another survey in western China [38]. The differences may be caused by different economic level of each area. The most stressful situation among the CHNs was "working environment and resources" issues, which is consistent with the studies conducted by Snelgrove [39], Asegid et al. [40] and Guo et al. [38]. In this study, "lack of protection laws when providing services for clients" was the most prominent problem among "working environment and resources" issues. This may be resulted from the fact that, in China the development of CHS started late for only 20 years and is still in immature stage which lacks sophisticated law and regulations, thus $\mathrm{CHNs}$ are not well protected and become nervous stressful during working. The second most stressful situation was "professional and career advancement". Studies conducted by Chen et al. [41] also identified it as the major stress issue. Nurses' workload in CHS centers or primary care settings were observed as the most common stressors by Han et al. [42] and Shihundla et al. [43]. However, this was neither identified in this study and nor by Galdikien et al. [44]. There were different work stress situation among nurses in CHS centers or primary care settings. This may be a focus of further investigations.
Job satisfaction among CHNs was in moderate degree: $58.2 \%$ of CHNs were in average level of job satisfaction, which is similar to those reported by Guo et al. [38] and Asegid et al. [40]. The two most satisfying aspects were "coworker relationships" and "recognition". Halcomb and Ashley [26] also identified that patient interactions, respect, teamwork were the most satisfying professional aspects. Harmonious relationships and being recognized by community residents may improve job satisfaction and promote the retention of CHNs. The CHNs were most dissatisfied with their "salary and benefits", which shows similarities with the study conducted by Kebriaei and Moteghedi [45]. This implied low income maybe a general concern to CHNs. Since low income can lead to low work-enthusiasm and high job burnout [46], income issues should be addressed by community administrators. The CHNs were also dissatisfied with their "work itself" and "professional development". They hold the opinions that their work environment was poor and had less chance for promotion compared with hospital nurses. This may harm to the cultivation of professional competence ability of CHNs and bring further work stress [47].

This study confirmed that there was a moderate significant negative correlation between work stress and job satisfaction, which might be harmful for the stability of human resources in the community because higher work stress can result in low satisfaction, and at the same time, it will lead to high turnover intention [2,48,49]. Stepwise multiple regression analyses showed that age, education, job training on community nursing, "professional and career advancement", "working environment and resources", "management and interpersonal relationships", "workload and time" were significant contributors to job satisfaction. Along with the growth of age, the perceptions of the older to job satisfaction is lower. In contrasted an earlier study by Cavanagh and Coffin [50] found higher educated hospital nurses had lower levels of job satisfaction. Such a difference may be accounted for by the fact that higher educated hospital nurses typically have complicated and multiple tasks including clinical and teaching responsibilities, research and so on, which can bring low levels of job satisfaction. Although the economic area of practice did not figure in the regression model, it was still noteworthy. Oneway-ANOVA method showed that the economic area of practice was significantly related to job satisfaction; mean scores of respondents from the provincial capital cities on job satisfaction were higher than those from the other cities. Given the rapid economic development of capital cities, the CHS centers developed quickly and could provide better community nursing for patients. Moreover, at the same time, more nurses in the provincial capital city have the opportunities to receive job training than those in other cities. Therefore, it may be reasonable that the job satisfaction of $\mathrm{CHNs}$ refusing job 
training is lower, since they would lack professional knowledge and skills in their daily work.

The four domains of work stress (i.e., "professional and career advancement", "management and interpersonal relationships", "working environment and resources", and "workload and time") were factors that predicted job satisfaction. This result was consistent with the report by Guo et al. [38] "Professional and career advancement" and "management and interpersonal relationships" were the most prominent factors in work stress that the CHNs perceived as capable of decreasing job satisfaction. Effective measures such as increasing opportunities for job training and continuing education, establishing reasonable salaries and promotion systems, and improving CHNs' public image should be implement. In addition, concerning management and interpersonal relationships, as CHS is complicated and involves face-to-face communication with coworkers such as physicians and pharmacists or administrators with distinct personalities; a warm and harmonious work environment that including create friendly work arrangements and strengthen colleague support should be took into account. These are consistent with studies demonstrated by Halcomb et al. and Bishwajit et al. [51]. Besides, some non-nursing tasks and paperwork were excessive and wasted the nurses' time. These results can be partly explained by the factors that affected job satisfaction. Of course, organizational commitment, turnover intention, job burnout, and other variables may also be important contributors to job satisfaction besides demographic profiles and work stress [51,52]. Thus, considering all aspects comprehensively should be encouraged to improve the job satisfaction of CHNs.

\section{Limitations}

This study should be considered by taking following limitations into account. Firstly, the results were based on a convenience sample because of limited time, space, and personnel. Secondly, although nurse managers received special online training, it was impossible to exclude bias when managers explained procedures and questionnaires to CHNs.

\section{Conclusion}

Our present study provided the first- hand documentation involved in work stress and job satisfaction of CHNs in Southwestern China, which showed a negative correlation between work stress and job satisfaction. Based on our finding, better approaches to releasing work stress, increasing opportunities for job training and continuing education, raising salary and improving promotion system should be therefore highly warranted.

\section{Implications for Nursing Management}

Considering that work stress can result in decreasing job satisfaction, measures should implement to improve CHNs' job satisfaction in the following ways. Firstly, improving the problem-solving abilities of CHNs in professional and career advancement by increasing financial support and opportunities for job training to retain and maximize the skills of CHNs. Secondly, regarding management and interpersonal relationships, CHNs should be encouraged to establish friendly relationships with coworkers, administrators, and other staff members who work in the CHS centers. Thirdly, improving the work environment and broadening access to appropriate resources and in the meantime, developing regulations to improve the feelings of security and the convenience of when CHNs are traveling for home visits by providing vehicles could be useful. Fourthly, to solve the problems associated to the assigned workload, unreasonable work and overtime work should be limited or avoided completely.

\section{Acknowledgment}

None

\section{Conflict of Interest}

None

\section{Source of Funding}

This study was supported by the China Medical Board (CMB). The CMB grant fund (11-085) is being made in response to the proposal "The development of the Chinese Innovative Practice Model of Community Health Nursing."

\section{Ethical Approval}

Ethical approval for the study was obtained from the clinical trial and biomedical ethics committee of West China hospital, Sichuan University. Approval letter: 2015 audit number (110).

\section{References}

1. Lim J, Bogossian F, Ahern K. Stress and coping in Australian nurses: a systematic review. Int Nurs Rev 2010; 57: 22-31.

2. Khamisa N, Peltzer K, Ilic D, Oldenburg B.. Work related stress, burnout, job satisfaction and general health of nurses: A follow-up study. Int J Nurs Pract 2016; 22: 538-545.

3. Dagget T, Molla A, Belachew T. Job related stress among nurses working in Jimma Zone public hospitals, South West Ethiopia: across sectional study. BMC Nurs 2016; 15: 39.

4. Feskanich D, Hastrup JL, Marshall JR, Colditz GA, Stampfer MJ, Willett WC, Kawachi I. Stress and suicide in the nurses health study. J Epidemiol Community Health 2002; 56: 95-98.

5. Negeliskii $\mathrm{Cm}$ Lautert L. Occupational stress and work capacity of nurses of a hospital group. Rev Latino-Am Enfermagem 2011; 19: 606-613.

6. Paille P. Perceived stressful work, citizenship behavior and intention to leave the organization in a high turnover environment: Examining the mediating role of job satisfaction. J Manag Res 2010; 3: 1-14. 
7. Yang H, Lv J, Zhou X, Liu H, Mi B. Validation of work pressure and associated factors influencing hospital nurse turnover: a cross-sectional investigation in Shaanxi Province, China. BMC Health Serv Res 2017; 17: 112.

8. Ellenbecker CH, Porell FW, Samia L, Byleckie JJ, Milburn M. Predictors of home healthcare nurse retention. J Nurs Scholarsh 2008; 40: 151-160.

9. Al Maqbali MA. Factors that influence nurses job satisfaction: a literature review. Nurs Manag (Harrow) 2015; 22: 30-37.

10. Cheung T, Yip PS. Depression, anxiety and symptoms of stress among hong kong nurses: a cross-sectional study. Int J Environ Res Public Health 2015; 12: 11072-11100.

11. Lu M, Ruan H, Xing W, Hu Y. Nurse burnout in China: a questionnaire survey on staffing, job satisfaction, and quality of care. J Nurs Manag 2015; 23: 440-447.

12. Clegg A. Occupational stress in nursing: a review of the literature. J Nurs Manag 2001; 9: 101-106.

13. Lu H, Barriball KL, Zhang X, While AE. Job satisfaction among hospital nurses revisited: a systematic review. Int J Nurs Stud 2012; 49: 1017-1038.

14. Phillips CB, Pearce C, Hall S, Kljakovic M, Sibbald B. Enhancing care, improving quality: the six roles of the general practice nurse. Med J Aust 2009; 191: 92-97.

15. Wu J, Zhang S, Chen H, Lin Y, Dong X, Yin X, Lu Z, Cao S. Patient satisfaction with community health service centers as gatekeepers and the influencing factors: a crosssectional study in Shenzhen, China. PLoS One 2016; 11: 0161683

16. Toofany S. Do district nurses have a public health role? Primary Health Care 2007; 17: 21-24.

17. Bekemeier B, Walker Linderman T, Kneipp S, Zahner SJ. Updating the definition and role of public health nursing to advance and guide the specialty. Public Health Nurs 2015; 32: $50-57$.

18. Fulmer H. History of visiting nurse work in America. Home Healthc Now 2017; 35: 33-42.

19. McTiernan K, McDonald N. Occupational stressors, burnout and coping strategies between hospital and community psychiatric nurses in a Dublin region. J Psychiatr Ment Health Nurs 2015; 22: 208-218.

20. Roden J, Jarvis L, Campbell-Crofts S, Whitehead D. Australian rural, remote and urban community nurses health promotion role and function. Health Promot Int 2016; 31: 704-714.

21. Prosser D, Johnson S, Kuipers E, Szmukler G, Bebbington P, Thornicroft G. Mental health,burnout and job satisfaction among hospital and community-based mental health staff. Br J Psychiatry 1996; 169: 334-337.

22. Leung SK, Spurgeon PC, Cheung HK. Job satisfaction and stress among ward-based and community-based psychiatric nurses. Hong Kong J Psych 2007; 17: 45-54.

23. Ball J, Pike G, Sethi G. Survey of district and community nurses in 2013: report to the Royal College of Nursing London 2014.
24. Al-Makhaita HM, Sabra AA, Hafez AS. Predictors of work-related stress among nurses working in primary and secondary health care levels in Dammam, Eastern Saudi Arabia. J Family Community Med 2014; 21: 79-84.

25. Sacks E, Alva S, Magalona S, Vesel L. Examining domains of community health nurse satisfaction and motivation: results from a mixed-methods baseline evaluation in rural Ghana. Hum Resour Health 2015; 13: 81.

26. Halcomb E, Ashley C. Australian primary health care nurses most and least satisfying aspects of work. J Clin Nurs 2017; 26: 535-545.

27. Boswell CA. Work stress and job satisfaction for the community health nurse. J Community Health Nurs 1992; 9: 221-227.

28. Delp L, Wallace SP, Geiger-Brown J, Muntaner C. Job stress and job satisfaction: home care workers in a consumer-directed model of care. Health Serv Res 2010; 45: 922-940.

29. National Health and Family Planning Commission of the People's Republic of China (NHFPC). Ann Stat Nat Health Fam Plan China 2016.

30. Gong MY, Huang YQ, Li XR. Research on the influence of professional identity and job stressors on job burnout among community nurses in Shenzhen. J Nurs Admin 2013; 13: 1-2.

31. Tang N, ShenQ, Deng JY, Lan YP, Xu F, Liao JL, Cai WZ. Job satisfaction, work retention and intention to quit of CHNs in Futian, Shenzhen. Chin Gene Pract Nurs 2015; 13: 300-303.

32. Tao L, Liu SZ. Literature anaIysis on the study of community nurses job satisfaction status quo in China. Chinese Nurs Res 2017; 31: 1267-1269.

33. Li XM, Liu YJ. Job stressors and burnout among staff nurses. Chinese J Nurs 2000; 35: 645-649.

34. Ayamolowo SJ, Irinoye O, Oladoyin MA. Job satisfaction and work environment of primary health care nurses in Ekiti State, Nigeria: an Exploratory Study. Int J Caring Sci 2013; 6: 531-542.

35. Tao H, Hu JC, Wang L, Liu XH. Development of a scale for job satisfaction assessment in nurses. Acad J Second Milit Med Univ 2009; 30: 1292-1296.

36. Ellenbecker CH, Byleckie JJ, Samia LW. Further psychometric testing of the home healthcare nurse job satisfaction scale. Res Nurs Health 2008; 31: 152-164.

37. Moses XJ, Walters KM, Fisher GG. What factors are associated with occupational health office staffing, job stress, and job satisfaction? J Occup Environ Med 2016; 58: 567-574.

38. Guo Y, Jiang WH, Li XM, Li J, Shi QF, Lv AL, Yu XF. The influence of job stressors on job satisfaction of community nurses in Xi an. J Nurs Admin 2016; 16: 1-3.

39. Snelgrove SR. Occupational stress and job satisfaction: a comparative study of health visitors, district nurses and community psychiatric nurses. J Nurs Manag 1998; 6: 97-104. 
40. Asegid A, Belachew T, Yimam E. Factors influencing job satisfaction and anticipated turnover among nurses in Sidama zone public health facilities, South Ethiopia. Nurs Res Pract 2014; 1-26.

41. Chen XX, Luo JZ, Su Y, Wang YH, Zhu LP. Relationship between occupational stress and mental health in community nurses. J Nurs Sci 2010; 25: 63-66.

42. Han JF, Li XH. An analysis on the job stressors of community health nurses. Chinese Nurs Manag 2007; 7 : 46-48.

43. Shihundla RC, Lebese RT, Maputle MS. Effects of increased nurses workload on quality documentation of patient information at selected Primary Health Care facilities in Vhembe District, Limpopo Province. Curationis 2016; 39: 1545.

44. Galdikien N, Asikainen P, Balčiūnas S, Suominen T. Do nurses feel stressed? a perspective from primary health care. Nurs Health Sci 2014; 16: 327-334.

45. Kebriaei A, Moteghedi MS. Job satisfaction among community health workers in Zahedan District, Islamic Republic of Iran. East Mediterr Health J 2015; 15: 1156-1163.

46. Cagan O, Gunay O. The job satisfaction and burnout levels of primary care health workers in the province of Malatya in Turkey. Pak J Med Sci 2015; 31: 543-547.

47. Wu YJ, Wang YH, Song YQ, Chen GL, Shen WL. Qualitative study of role functions of community health nurses in the team work model. J Nurs Admin 2011; 11: 383-385.
48. Tourangeau AE, Patterson E, Saari M, Thomson H, Cranley L. Work-related factors influencing home care nurse intent to remain employed. Health Care Manage Rev 2015; 42: 87-97.

49. Lu Y, Hu XM, Huang XL, Zhuang XD, Guo P, Feng LF, Hu W, Chen L Hao YT. Job satisfaction and associated factors among healthcare staff: a cross-sectional study in Guangdong Province, China. BMJ Open 2016; 6: 011388.

50. Cavanagh SJ, Coffin DA. Staff turnover among hospital nurses. J Adv Nurs 1992; 17: 1369-1376.

51. Bishwajit M, Khumyu A, Boonyanurak P. Relationships between organizational commitments, supervisory support and job satisfaction of nurses in a public specialized hospital, Bangladesh. Bangl J Med Sci 2016; 15: 39-43.

52. Chen J, Lu Q, Ying SY, Li XG, Wen CJ, Pang D. Professional identity, job stress, job satisfaction and turnover intention among nurses. Chinese Nurs Manag 2012; 12: 43-46.

\section{*Correspondence to}

Suzhen Liu

West China Hospital/West China School of Nursing

Sichuan University

PR China 